\title{
Reform and Innovation of Mechanical Practice Teaching JIN Chenggong
}

\author{
Beihua University Engineering Training Center, JiLin, 132021, China
}

\author{
Keywords: Experimental teaching; Reform research; Practice mode
}

\begin{abstract}
Mechanical courses can not only teach students of theoretical knowledge, only the experimental teaching fully integrated into the mechanical class teaching model, will be better to play the value of mechanical courses teaching. In this paper, the experimental construction of mechanical courses for a simple analysis, and how to strengthen the extracurricular open experiment and design innovative experiments and other specific elaboration.
\end{abstract}

\section{Introduction}

Mechanical engineering is an important symbol of China's industrial development, at present, the industry needs a strong professional ability of mechanical engineering professionals. Whether in the teaching of mechanical courses or in the actual experimental management, need to continue to use innovative teaching mode, so as to better promote China's mechanical courses to achieve progress and development. Practical teaching and theoretical teaching in fact there is a big gap between the statistics show that China is now most of the colleges and universities in teaching are too much emphasis on the teaching of theoretical knowledge, but ignored the cultivation of students' practical ability. There are significant differences between mechanical courses and other categories of courses. First, mechanical courses have greater diversity. If they can not use practical teaching methods, they tend to reduce the students' grasp of the curriculum. Practical teaching is the deepening of theoretical teaching, but also the theory of practice with the most effective and most direct means. Can be seen in the actual teaching, into the practical teaching is very necessary.

\section{Strengthen the Construction of Experimental Teaching System}

Strengthening the construction of experimental teaching system is an important goal to promote the development of mechanical courses in colleges and universities in China. Compared with the traditional teaching objectives, some colleges and universities in our country now have higher requirements for teaching reform. In order to achieve the goal of cultivating diversified talents, the mechanical major in most colleges and universities in our country has formulated a certain teaching mode and teaching system. Some mechanical majors have set up corresponding experimental courses to enhance students' awareness of the importance of experimental teaching by strengthening the research and development of experimental projects. To fully integrate the theory and practice, remember not to use a single teaching model, for students, only the theoretical knowledge of teaching, will only cause students to resent. If you can integrate the content of practice in theoretical teaching, will be to a large extent to enhance the enthusiasm of students for mechanical courses. It can be seen that it is very important to strengthen the construction of the experimental teaching system and perfect the existing teaching system of mechanical courses.

\section{Strengthening the Experimental Teaching Management System of Mechanical Courses}

In the construction of experimental teaching of mechanical courses, we must pay attention to the construction of experimental teaching management system, because only the perfect teaching system and teaching system can lay a solid foundation for cultivating high quality and diversified talents. The establishment of the mechanical experiment teaching course involves many aspects. First of all, in order to establish the standardized and orderly experimental concept of students, we should regularly organize some experimental open classes, observe the class, if the conditions 
should also be held every year Experimental Teaching Quality Feedback. Which can be to enhance the mechanical class experimental teaching management system to give strong protection. In addition, colleges and universities should also establish and improve the experimental teaching evaluation system of mechanical courses, the evaluation system is not only to study the students for the mechanical class experimental teaching awareness, more is to examine the comprehensive ability of students, of which Including research capacity, classroom practice capacity, professional ethics and skills and many other aspects. Only do this, will continue to promote China's mechanical curriculum experimental teaching to achieve efficient development. In order to stimulate students' awareness of mechanical courses, teachers should also regularly develop peer evaluation and student evaluation system, so that students learn more about mechanical courses, in the discovery of the problem at the same time, in a timely manner to solve the problem But also mechanical class teaching involved in the important content.

\section{Establish a Reasonable Mechanical Experimental Teaching System}

Reasonable mechanical experiment teaching system is the main content to promote the reform and development of the experimental teaching of mechanical course in China. Under normal circumstances, the mechanical experimental teaching system will be divided into a number of teaching objectives, including awareness - understanding - accumulation - creation, these are mechanical courses in the experimental teaching of the main content. For the development of the experimental teaching system of mechanical courses, the innovative teaching mode is very important. To stimulate students' awareness and understanding of the mechanical courses, students should be trained on the experimental level of students at the same time. Continuous training and practice to enhance their own understanding of the mechanical class. Under normal circumstances, the mechanical courses involved in the practice are more complex, which not only requires students to know a certain degree of professional theoretical knowledge, but also should understand the principle of mechanical courses, only the comprehensive ability, in order to better Accept and study mechanical experiments. In addition, the mechanical teaching also involves a lot of experimental courses, students and students to learn to unite and explore, many times the mechanical experiment alone can not be completed alone, but the need for multiple students to work together for the students, not only to cultivate the practical ability, but also exercise the ability to cooperate. Only for the multi-disciplinary innovation team to provide better services, will be engaged in innovative research and entrepreneurial practice to provide more favorable conditions. In the daily teaching mode, the scientific and rational development of the mechanical experimental teaching system needs to integrate many modern teaching modes, because many times the use of multimedia and information technology teaching can effectively improve the teaching efficiency, in order to achieve the mechanical class teaching system Development lay a solid foundation.

\section{Strengthen Extracurricular Open Experiment and Design Innovative Experiment}

Extracurricular Open Experiment. The results of the survey show that many college students now lack the extracurricular experimental study, because most of the schools in the extra-time laboratory are in a closed state, which also for many students to study and experimental research has caused a certain Obstruction. For most students, if you can learn more about the experiment in extra time, it will be of great help to the study of mechanical courses. Extracurricular open experiment is mainly to allow students in the spare time to come to the laboratory more contact with a variety of advanced equipment and equipment. For example, learn more about the use of CAM / CAD software, learn more about laser engraving, rapid prototyping, CNC machining and other modern equipment operation, these are mechanical courses in the main content of teaching. Sometimes the study of mechanical courses involves a very wide range of content, if the students lack of understanding and understanding of experimental equipment, will affect students' awareness of mechanical courses. It can be seen that it is important to strengthen students' understanding of laboratory equipment and equipment in practical teaching. Strengthening extra-curricular 
experiment and designing innovative experiment is a more important link in the development of modern teaching system. For most students and teachers, extra-curricular experiment will provide more protection for students' learning and development. Extracurricular opening experiments tend to attract students' attention. For many colleges and universities, laboratory equipment and equipment are limited, in order to avoid damage to equipment and equipment, teachers often do not let students free to experiment. If you can open the laboratory in the classroom, it will provide students with more hands-on opportunities, we can see the opening of extracurricular experimental class is very necessary.

The Design of Innovative Experiments. Innovative experiment has a great influence on the development of mechanical teaching system. From a macro point of view, innovative experiments for students often have a high demand. Design Innovative experiment is a kind of experiment which requires a higher capacity for students' comprehensive ability. Compared with the traditional experiment, the innovative experiment is between scientific experiment and basic teaching experiment, which requires students not only to master some basic Mechanical class curriculum expertise, but also should master some interdisciplinary content. Many times the innovative experiment requires students to master their own professional knowledge of the theory, but also the overall quality of their students have a higher demand. The only way to continue to inspire students to learn the enthusiasm and creativity. Under normal circumstances, innovative experiments on the comprehensive ability of students have a higher demand, in order to cultivate college students scientific and rational grasp of mechanical class experimental teaching model, first of all should require students to have a realistic style of work and rigorous scientific attitude, these Is to promote the long-term development of China's scientific undertakings an important guarantee. In today's society, innovative experiments are needed for social development and a new requirement for mechanical courses in construction. If the experiment is not innovative, then the machinery industry will not have a greater development, so in order to promote the machinery industry innovation and development, it should continue to adopt new ideas to innovation, so as to achieve the full range of mechanical courses Orientation development.

The Establishment of Teacher and Student Exchange Platform. Sometimes for college students of mechanical engineering, just rely on theoretical knowledge and practical teaching is not enough, in the face do not understand the problem, the students also need the first time to communicate and communicate with the teacher. Especially in the practice of teaching, when students encounter problems or difficulties, teachers should be the first time with the students to communicate and communicate in a timely manner to solve the problems of students, so as to better help teachers to achieve teaching objectives. In the modern 21st century, information technology teaching mode and multimedia teaching have been integrated into the teaching industry, which also for the mechanical courses of practical teaching has brought greater room for development. Therefore, the author suggested that the relevant colleges and universities should establish a platform for information exchange between teachers and students, so as to open communication between teachers and students to open up new ways. In colleges and universities, teachers are usually only in contact with students in class, less contact under the class. In order to increase the opportunity for students to communicate with teachers, it is necessary to establish a communication platform between teachers and students to lay a solid foundation for the efficient development of experimental teaching of mechanical courses. In the mechanical class experiment teaching, students often encounter a variety of problems, such as for experimental equipment do not understand the content of the experiment is not in place, etc., these problems may occur in experimental teaching. Therefore, the establishment of information exchange platform between teachers and students is essential, so that you can cultivate a strong professional ability to give students more favorable protection.

\section{Conclusion}

In summary, the author briefly discusses the reform of the experimental teaching of mechanical courses in major colleges and universities in recent years. Through analysis, it can be found that the 
teaching of mechanical courses in our country has been improved in the field of innovation, whether teachers or students, Have been recognized the importance of experimental teaching. For students, experimental teaching will be for their own future development play a catalytic role. And only have the spirit of innovation and engineering practice, will have a better development prospects. It can be seen that the experimental teaching model plays an important role in the teaching of mechanical class experiment.

\section{References}

[1] Xi Ping Yang Yang Wang Chunjie Reform and practice of experimental teaching of mechanical course [J]. Experimental technology and management,2010,27(07):14-18.

[2] Liu Lingling Zhou Zhijin Reform and practice of experimental teaching of mechanical principle[J]. Mining engineerin gresearch,2008,30(01):146-148.

[3] Li Wenfang The idea and practice of innovation experiment in mechanical design curriculum [J].Journal of Putian University,2005,12(05):85-87.

[4] Liu Defu He Yuhui Exploration and practice of hierarchical and modular experimental teaching system reform of mechanical engineering courses [J].Journal of Changsha Railway Institute: Social Science Edition, 2012,13(01):79-82. 